Roberta de Freitas ${ }^{1}$

\title{
DIREITO SANITÁRIO GLOBAL: \\ TEMAS, ATORES E PROCESSOS
}

Global health law: issues, actors and processes

${ }^{1}$ Universidade de São Paulo. São Paulo/SP, Brasil.

Correspondência: Roberta de Freitas. E-mail: roberta.freitas@fiocruz.br.

Recebido em: 26/11/2015. Revisado em: 18/04/2016. Aprovado em: 19/04/2016. 


\section{RESUMO}

Proteger a saúde pública e melhorar os indicadores individuais de saúde envolve cada vez mais inovações na legislação nacional e internacional. Além das tradicionais organizações internacionais voltadas para a saúde (Organização Pan-Americana da Saúde, Organização Mundial da Saúde), nota-se no cenário global um incremento de outros atores que dispõem de normas e regulamentos próprios e que repercutem e interferem de forma direta ou indireta na área da saúde, tais como a Organização Mundial do Comércio, o Banco Mundial, fundações privadas etc. O presente artigo não tem por objetivo esgotar a reflexão conceitual sobre o Direito Sanitário Global, mas procura caracterizá-lo a partir de três elementos que o integram: temas, atores e processos políticos de negociação.

\section{Palavras-Chave}

Direito Sanitário Global; Direito Sanitário Internacional; Jurisprudência sobre Saúde Global; Legislação sobre Saúde Global.

\section{ABSTRACT}

Protection of public health and improvement individual health indicators increasingly involve innovation in national and international legislation. In addition to traditional international organizations focused on health (Pan American Health Organization, World Health Organization), an increase has been observed among other actors with their own rules and regulations that directly or indirectly have repercussion and impact on healthcare, such as the World Trade Organization, the World Bank, private foundations, etc. This article does not intend to provide an exhaustive account of a conceptual thought on Global Health Law, but aims to give an overview of it according to three of its essential features: themes, actors and political processes of negotiation.

\section{Keywords}

Global Health Law; International Health Law; Global Health Jurisprudence; Global Health Legislation. 


\section{Introdução}

A saúde é um direito humano essencial para o exercício de todos os direitos humanos. O tema é de primeira ordem na agenda política, nacional e internacional, manifestando-se como uma questão social com amplas influências da globalização.

Vários temas em debate nas agendas internacionais dialogam com o direito à saúde e têm impacto sobre ele. Além dos Estados nacionais, garantidores legítimos desse direito, outros atores internacionais são capazes de influenciar a definição de normas internacionais que impactam a saúde.

As implicações da participação e influência desses outros atores fazem surgir na literatura novos conceitos, como saúde global e Direito Sanitário Global - o que suscitou a preocupação em compreender este conceito e as consequências de sua utilização de forma acrítica.

O presente artigo, construído através da revisão sistemática de literatura, não tem por objetivo esgotar a reflexão conceitual sobre o Direito Sanitário Global, mas procura caracterizá-lo a partir de três elementos que o integram: (I) Temas; (II) Atores; e (III) Processos políticos de negociação.

\section{Direito Sanitário Global}

A evolução da consciência global sobre o direito humano à saúde coincide com a percepção sobre suas interfaces na esfera política, econômica, de segurança etc. A atual compreensão da saúde como um bem público global faz com que as políticas públicas sejam baseadas em direitos humanos e utilizem mecanismos de construção de cidadania e participação política, daí a necessidade de promovê-los, além de desenvolver ações para evitar sua violação nos sistemas de saúde.

A globalização, como apontado por Ruggie ${ }^{1}$, é marcada por características de crescente interdependência econômica, política e social, bem como pela integração global do capital, de bens de capital, de conceitos, de ideias, de valores e de pessoas, o que repercute no aumento do risco da propagação internacional de doenças infecciosas e não transmissíveis. Tais características levaram a importantes mudanças na organização, no financiamento e nas ações dos sistemas nacionais de saúde. O comércio, as viagens, as questões ambientais, os conflitos armados e o terrorismo transcendem os limites territoriais e impactam profundamente a saúde individual e comunitária, o que representa "riscos e oportunidades interligadas que afetam a sustentabilidade dos sistemas de saúde em todo o mundo"2.

\footnotetext{
${ }^{1} \mathrm{RUGGIE}, \mathrm{J}$. At home abroad, abroad at home: international liberalization and domestic stability in the new world economy. Millennium: journal of international studies, v. 24, n. 3, p. 507-526, 1994. Disponível em: <http://journals.sagepub.com/doi/pdf/10.1177/03058298950240031301>.

${ }^{2}$ YACH, D; BETTCHER, D. A globalização da saúde pública 1: ameaças e oportunidades. Jornal Americano de Saúde Pública, p. 735-738. 1998.
} 
No século XXI, alguns autores, como Stephen e Daibes, entendem que o fenômeno da globalização ou sua intensificação alterou a tradicional distinção entre saúde internacional e saúde global:

Isso, de certa forma, significa uma mudança do pensamento de "saúde internacional", que se preocupa principalmente com o controle da propagação de epidemias através das fronteiras nacionais, para "saúde global", que se preocupa com a saúde da população mundial conforme as forças da globalização se tornam mais fortes ${ }^{3}$. (Tradução livre)

É importante tecer algumas reflexões sobre saúde global, termo que não é utilizado simplesmente com o objetivo de renovar a literatura substituindo a expressão "saúde internacional". Conforme comentado por Godue:

Muitas vezes a expressão "saúde global" aparece em substituição à ideia de "saúde internacional", termo criado no início do século passado (em 1913, nos Estados Unidos, no âmbito da Fundação Rockfeller) e que até os anos de 1990 foi utilizado para se referir à saúde como um fenômeno transnacional, mas sem considerá-la como algo a ser tratado no âmbito das relações internacionais, isto é, das relações entre Estados nacionais integrantes de um sistema mundial hierarquizado e iníquo ${ }^{4}$.

A caracterização da saúde global parte de uma compreensão sistêmica da saúde e da sociedade contemporânea, que reconhece não somente o encurtamento das distâncias, mas também se vincula ao:

Impacto de la interdependencia global sobre los determinantes de la salud, la transferencia de riesgos de salud y la respuesta en la forma de políticas de las naciones, de las organizaciones internacionales y de los múltiples actores en el entorno de la salud global ${ }^{5}$.

O termo "saúde global", além de reconhecer a participação de outros atores com importância, enfoques, estratégias e objetivos variados - como fundações privadas, organismos não governamentais e grandes corporações - nos fóruns e

\footnotetext{
3.This, to some extent, signifies a shift in thinking from 'international health' which concerns itself primarily with the control of the spread of epidemics across national boundaries to 'global health,' which concerns itself with the health of the global population as the forces of globalization become stronger". STEPHEN, C.; DAIBES, I. Defining features of the practice of global health research. Global Health Action, n. 3, 2010. Disponivel em: <http://www.globalhealthaction.net/index.php/gha/article/view/5188/5772>. Acesso em: 10 out. 2013.

${ }^{4}$ Apud ALMEIDA, Celia. A experiência da Fiocruz na formação de profissionais em saúde global e diplomacia da saúde: base conceitual, estrutura curricular e primeiros resultados. Reciis, Rio de Janeiro, v. 4, n. 1, p. 148-164, mar. 2010. Fundação Oswaldo Cruz. Disponível em: <http://www.reciis.icict.fiocruz.br/index.php/ reciis/article/view/721/1366>. Acesso em: 10 set. 2013. 10.3395/reciis.v4i1.355pt.

${ }^{5} \mathrm{KICKBUSCH}, \mathrm{I}$. Action on global health: addressing global health governance challenges. Public Health, v. 19, n. 119, p. 969-973, 2005. http://dx.doi.org/10.1016/j.puhe.2005.08.008.
} 
discussões sobre saúde, ademais dos Estados e organismos internacionais, também realça a relevância desses outros atores para dar mais legitimidade à governança global da saúde ${ }^{6}$, uma vez que os problemas de saúde se relacionam com muitos outros aspectos sociais, econômicos e políticos.

Kickbusch discorre que "saúde global" se define "pela interação complexa entre o Estado e atores não estatais através de novos mecanismos organizacionais que permitem a participação deles. Onde o novo sistema é plural e caracterizado por uma crescente privatização ${ }^{7 ”}$ (tradução livre). Suscitamos, porém, que nesses casos a legitimidade da participação desses "novos atores" deve ser ponderada nos limites de seus interesses econômicos.

Nesse sentido, Gostin define o Direito Sanitário Global incluindo esses três aspectos a serem abordados:

O Direito Sanitário Global é um campo que abrange as normas, os processos e as instituições jurídicos necessários para criar as condições para que pessoas de todo o mundo alcancem o nível mais alto possível de Saúde física e mental ${ }^{8}$. (Tradução livre)

Diante dessa realidade, as normas e políticas públicas de saúde são cada vez mais transnacionais. Com uma infinidade de organizações internacionais que compartilham autoridade legislativa sobre a saúde, bem como outros atores envolvidos que influem no processo legislativo internacional da saúde, a expansão da legislação sanitária internacional se mostra fragmentada, descoordenada e ineficaz ${ }^{9}$.

\section{Temas}

A abordagem abrangente do Direito Sanitário Global envolve vários temas inter-relacionados, incluindo saúde, segurança, meio ambiente, política, comércio, economia, propriedade intelectual, direitos humanos, ética e segurança nacional:

\footnotetext{
${ }^{6}$ Segundo Buss et al.: “Entende-se por 'governança global da saúde' os arranjos institucionais existentes com vistas à condução dos assuntos internacionais e globais na área da saúde, entre eles o da saúde humana e ambiente." BUSS, Paulo Marchiori et al. Governança em saúde e ambiente para o desenvolvimento sustentável. Ciênc. saúde coletiva, v. 17, n. 6, p. 1479-1491, 2012. Disponível em: <http://www.scielosp.org/pdf/csc/v17n6/ v17n6a12.pdf>. Acesso em: 15 out. 2013. http://dx.doi.org/10.1590/S1413-81232012000600012.

7“[...] through a complex interplay between state and non-state actors and through new organisational mechanisms that allow for their involvement. The new global health system is clearly pluralistic and characterized by increasing privatisation". (KICKBUSCH, I. Action on global health: addressing global health governance challenges, cit., p. 970).

${ }^{8}$ GOSTIN, L.O; TAYLOR, A. L. Global health law: a definition and grand challenges. Public Health Ethics, v. 1, n. 1, p. 53-63, 2008. Disponível em: <https://academic.oup.com/phe/article-lookup/doi/10.1093/phe/ phn005>. https://doi.org/10.1093/phe/phn005.

${ }^{9}$ TAYLOR, A. L. Global governance, international health law and WHO: looking towards the future. Bull World Health Organ, v. 80, n. 12, p. 1-5, Jan. 2012. Disponível em: <http://www.scielosp.org/scielo. php?script=sci_arttext\&pid=S0042-96862002001200013\&lng=en\&nrm=iso>. Acesso em: 30 ago. 2013. http://dx.doi.org/10.1590/S0042-96862002001200013.
} 
Hoje, o florescente campo do direito sanitário internacional engloba cada vez mais diversas e complexas preocupações, incluindo os aspectos da ciência biomédica, reprodução humana e clonagem, deficiência, doenças infecciosas e não transmissíveis e controle de segurança sobre serviços de saúde, alimentos e produtos farmacêuticos ${ }^{10}$. (Tradução livre)

No que diz respeito à política internacional, as articulações entre os Estados e os novos atores ${ }^{11}$ são adaptáveis, em certos contextos, aos interesses de reafirmar sua noção de soberania e cooperar perante interesses comuns.

Nos fóruns de negociações do G20, da Assembleia Geral das Nações Unidas, do Conselho de Chefes de Estado e de Governo da União das Nações Sul-Americanas (Unasul), do Conselho do Mercado Comum etc., assim como da Assembleia Mundial de Saúde ou mesmo do Conselho de Segurança da Organização das Nações Unidas (ONU), são possíveis conjunturas e alianças entre Estados variadas e, em muitos casos, contraditórias.

O tema da segurança se relaciona à saúde desde as mais remotas epidemias de que se tem registro, como a peste negra na Grécia relatada por Tucídides em 431 a.C.; a implementação das primeiras medidas de quarentena nos países da Europa e a construção de muralhas entre cidades para evitar pestes e epidemias durante a Idade Média; a realização da $1^{\text {a }}$ Conferência Sanitária, em 1851, em Paris, e suas conferências subsequentes que culminaram na criação do Comitê Sanitário Internacional e a Oficina Internacional de Higiene Pública, em 1902; o estabelecimento do $1^{\circ}$ Código Sanitário Pan-Americano, em 1924, com sua última revisão adotada internacionalmente em 2005; até os mais recentes episódios da síndrome respiratória aguda grave (SARS) em 2003, da influenza A (H1N1), em 2009; da gripe aviária (vírus H5N1 e H7N9), desde 2005, e do coronavirus (MERS-CoV) desde 2010 ${ }^{12}$.

Segurança e saúde envolvem, ainda, preocupações com armas químicas e biológicas utilizadas desde a Antiguidade, há mais de dois mil anos, quando os gregos utilizavam flechas envenenadas em suas guerras. Esse tipo de armamento também foi usado em larga escala na Primeira (gás cloro e gás

\footnotetext{
10“Today, the burgeoning field of international health law encompasses increasingly diverse and complex concerns, including aspects of biomedical science, human reproduction and cloning, disability, infectious and noncommunicable disease, and safety control for health services, foods and pharmaceuticals". (TAYLOR, A. L. Global governance, international health law and WHO: looking towards the future. Bull World Health Organ, v. 80, n. 12, p. 975, Jan. 2012. Disponível em: <http://www.scielosp.org/scielo. php?script=sci_arttext\&pid=S0042-96862002001200013\&lng=en\&nrm=iso>. Acesso em: 30 ago. 2013. http://dx.doi.org/10.1590/S0042-96862002001200013).

${ }^{11} \mathrm{~A}$ serem detalhados posteriormente.

${ }^{12}$ CASTRO, L. P. G; FERREIRA, F. P. 0 direito à saúde e a globalização. Revista Anhanguera, v. 11, n. 1, p. 61-87, dez. 2010.
} 
mostarda) e na Segunda Guerra Mundial (gás cianídrico), na Guerra do Vietnã (Napalm e agente laranja) e, mais recentemente, no atentado terrorista ao metrô de Tóquio, em 1995 (gás Sarin). Pode-se avaliar como um importante avanço a adesão formal da Síria à Convenção sobre Proibição de Armas Químicas da ONU, em outubro de 2013.

Outros eventos de saúde pública se seguem, com destaques preocupantes no cenário atual: vazamento de água radioativa e contaminação do ar pela usina de Fukushima ${ }^{13}$ e utilização desautorizada de tecnologia nuclear para fins militares em países como Coreia do Norte, Irã e Turquia ${ }^{14}$. Nos últimos anos, vem-se aumentando a preocupação com o uso de armas biológicas, especificamente a possibilidade do uso do vírus da varíola como agente infeccioso ${ }^{15}$; isso tem levado a inflexões no âmbito da própria Organização Mundial da Saúde (OMS), quando discussões acirradas entre Estados Unidos e Irã sobre a eliminação das cepas desse vírus, existentes apenas em dois laboratórios na Rússia e dos Estados Unidos ${ }^{16}$, se estendem desde $1996^{17,18}$.

Não há grande novidade em relação aos interesses comerciais que justifiquem a atuação de entidades e Estados relacionada à saúde pública. Como já comentado, o exemplo tradicional de risco e segurança sanitária no comércio internacional de mercadorias justificou, nos séculos passados, a imposição de quarentenas e medidas sanitárias em portos e zonas de intercâmbio comercial ${ }^{19}$.

Atualmente, em vários episódios relacionados ao comércio internacional são usados argumentos sanitários para a imposição de barreiras econômicas ou como justificativa nas disputas de interesses comerciais - como no caso dos pneus, discutido

${ }^{13}$ IAEA. INTERNATIONAL ATOMIC ENERGY AGENCY. Update on Seawater Radioactivity Concentrations at TEPCO's Fukushima Daiichi Nuclear Power Station. 2013. Disponível em: <https://www.iaea.org/ newscenter/news/2013/seamonitoring151013.pdf>. Acesso em: 16 out. 2013.

${ }^{14} \mathrm{De}$ acordo com o Tratado de Não Proliferação Nuclear (TNP), somente os países que explodiram a bomba atômica antes de $1^{\circ}$ de janeiro de 1967 (Estados Unidos, Rússia, China, Reino Unido e França) têm o direito de possuírem este tipo de armamento. BRASIL. Decreto n. 2.864, de 7 de dezembro de 1998. Promulga o Tratado sobre a Não-Proliferação de Armas Nucleares, assinado em Londres, Moscou e Washington, em $1^{\circ}$ de julho de 1968. Disponível em: < http://www.planalto.gov. br/ccivil_03/decreto/d2864.htm>. Acesso em: 31 jan. 2017.

${ }^{15}$ ATLAS, Ronald M. The threat of bioterrorism returns the fear of smallpox. Current Opinion in Microbiology, v. 1, 1998

${ }^{16}$ US Centre for Disease Control and Prevention (CDC), em Atlanta, nos Estados Unidos, e o State Research Institute for Viral Preparations (Vector), em Moscou, Rússia.

${ }^{17}$ WORLD HEALTH ORGANIZATION (WHO). Gar. Sistema global de alerta e respostas para epidemias e eventos de saúde pública, 2013. Disponível em: <http://www.who.int/csr/don/archive/year/2013/en/index. html>. Acesso em: 30 ago. 2013. WORLD HEALTH ORGANIZATION (WHO). Trade, foreign policy, diplomacy and health. International Law. Disponivel em: <http://www.who.int/trade/glossary/story061/en/index. html>. Acesso em: 05 set. 2013.

${ }^{18}$ TUCKER, Jonathan B. Breaking the deadlock over destruction of the smallpox virus stocks. Biosecurity and Bioterrorism: biodefense strategy, practice and science, v. 9, n. 1, p. 63, 2011.

${ }^{19}$ CASTRO, L. P. G; FERREIRA, F. P. op. cit., p. 61-87. 
em instâncias sobre comércio ${ }^{20}$, em que se entendeu que as medidas restritivas poderiam ser fundamentadas com base na proteção à saúde pública e ao meio ambiente ${ }^{21}$.

Conforme contextualizado por Rodrigues e Soler ${ }^{22}$, a ameaça de emissão de licença compulsória ${ }^{23}$ ou "quebra de patente" - prevista no Acordo de Propriedade Industrial (Trips) ${ }^{24}$ da Organização Mundial do Comércio (OMC) em casos de comercialização insatisfatória ou emergência nacional e interesse público - serviu como estratégia durante a negociação de preços de medicamentos antirretrovirais entre o governo brasileiro e as empresas farmacêuticas detentoras das patentes desses medicamentos em 2001, 2003 e 2005. Por sua vez, o Brasil recorreu a essa estratégia pela primeira vez em maio de 2007 a fim de obter permissão para importar e produzir versões genéricas do Efavirenz de laboratórios pré-qualificados pela Organização Mundial da Saúde ${ }^{25}$.

A utilização de normas sanitárias como barreira comercial foi ponto de tensão no "caso dos pepinos", em 2011, quando as autoridades da Alemanha anunciaram um alerta a países vizinhos para que retirassem pepinos orgânicos da Espanha de circulação, pois teriam sido identificados como uma fonte do surto de $E$. coli nesse país, levando a um quadro de mais de 2.600 casos e 12 mortes. Após análises bacteriológicas que confirmaram que as estirpes encontradas nos pepinos espanhóis não eram enterohemorrágicas, a Espanha exigiu ressarcimento dos danos causados pela emissão do alerta por parte da Alemanha.

Questões como migração e crise econômica representam impactos nos sistemas de saúde dos países. As evidências negativas mais atuais nos sistemas de saúde europeus começaram a ser observadas após a crise de 2008. Países como Espanha e França vêm sofrendo modificações em seus sistemas nacionais de saúde:

\footnotetext{
${ }^{20}$ Tribunal Arbitral Ad Hoc do Mercado Comum do Cone Sul (Mercosul) e Mecanismo de Solução de Controvérsias da OMC. (MERCADO COMUM DO CONE SUL. Laudos: protocolo de olivos para a solução de controvérsias no Mercosul: tribunal permanente de revisão. Montevideo, Mercosur. Disponível em: <http://www.mercosur.int/innovaportal/v/440/2/innova.front/laudos>. Acesso em 18 fev. 2017), e Mecanismo de Solução de Controvérsias da Organização Mundial de Comércio (OMC). (WORLD TRADE ORGANIZATION. Brazil: Measures affecting imports of retreaded tyres. Geneva, Switzerland: WTO. Disponível em: <https://www.wto.org/english/tratop_e/dispu_e/cases_e/ds332_e.htm>. Acesso em 18 fev. 2017.)

${ }^{21}$ MOROSINI, Fabio C. The MERCOSUR and WTO Retreaded Tires Dispute: Rehabilitating Regulatory Competition in International Trade and Environmental Regulation. In: INAUGURAL CONFERENCE, 2008, Switzerland. Geneva: Society of International Economic Law (SIEL). Disponivel em: <https://papers.ssrn.com/sol3/ papers2.cfm?abstract_id=1154710\#\#>. Acesso em: 18 fev. 2017. http://dx.doi.org/10.2139/ssrn.1154710.

${ }^{22}$ RODRIGUES, W. C. V.; SOLER, O. Licença compulsória do efavirenz no Brasil em 2007: contextualização. Revista Panamericana de Salud Publica, v. 26, n. 6, p. 553-559, 2009.

${ }^{23}$ Significa suspensão temporária do direito de exclusividade do titular de uma patente, permitindo a produção, uso, venda ou importação do produto ou processo patenteado, por um terceiro, sem a autorização do titular da patente.

${ }^{24}$ INSTITUTO NACIONAL DE PROPRIEDADE INDUSTRIAL. Decreto n. 1.355, de 30 de dezembro de 1994. Promulgo a Ata Final que Incorpora os Resultados da Rodada Uruguai de Negociações Comerciais Multilaterais do GATT. Disponível em: <http://www.inpi.gov.br/legislacao-1/27-trips-portugues1.pdf>. Acesso em: 31 jan. 2017.

${ }^{25}$ BERMURDEZ, J. A. Z; OLIVEIRA, M. A; CHAVES, G. C. O Acordo TRIPS da OMC e os desafios para a saúde pública. In: BERMUDEZ, Jaz; OLIVEIRA, M; ESHER, A. (Orgs.). Acceso a medicamentos: derecho fundamental, papel del Estado. Rio de Janeiro: Escola Nacional de Saúde Pública, Fundação Oswaldo Cruz, 2004. p. 69-89.
} 
Com o início da crise econômica, todos esses avanços históricos do SNS estão sendo ameaçados, com precarização dos serviços, privatização de serviços da saúde pública, diminuição dos pagamentos dos profissionais de saúde e aumento de suas horas de trabalho ${ }^{26}$.

O surgimento ou a intensificação das Doenças Crônicas não Transmissíveis (DCNT) e o envelhecimento populacional trazem à tona estilos de vida importados e/ou intensificados pela globalização. Essa preocupação acompanha as discussões sobre a regulação e o consumo de tabaco, álcool, medicamentos, sal etc., bem como o uso de propagandas e tecnologias de comunicação cada vez mais em benefício de grandes conglomerados econômicos.

Todos esses temas, e outros não aprofundados neste artigo, apresentam estreito nexo e interdependência entre si, com a saúde e com o Direito Sanitário. A Figura 1 ilustra essa complexidade:

Comércio/Política

- Propriedade intelectual (TRIPS)

- Proteção de mercados internos

Estilos de Vida

- Tabaco

- Álcool

- Alimentação

- Medicação

Meio Ambiente

- Agrotóxicos

- Água

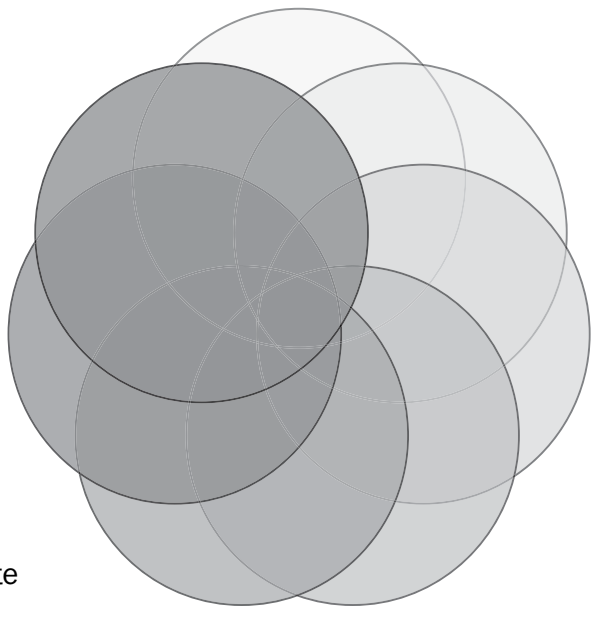

Segurança

- Epidemias

Informação e

- Armas Químicas/Nucleares

$-\mathrm{Ar}$

Conflitos Armados

- Refugiados

- Migração

Desenvolvimento

- Sustentável

- Ciência e tecnologia

- Mobilidade

Figura 1. Temas inter-relacionados com a saúde e o Direito Sanitário Global.

\footnotetext{
${ }^{26}$ FERNANDEZ, L. A. L. A crise econômica Europeia e as repercussões nos sistemas de saúde. São Paulo, Conferência, 21, nov. 2012. Conferência realizada na Faculdade de Saúde Pública da Universidade de São Paulo.
} 
Tais questões têm pautado as agendas internacionais e nacionais. A preocupação com temas como desenvolvimento, mobilidade urbana, poluição, uso de agrotóxicos, qualidade do ar, água, produção e consumo sustentáveis foi o principal ponto da Rio +20, e está profundamente relacionada à saúde e às condições de vida das populações; em que pese o esforço para se incluir o tema no documento final dessa conferência ${ }^{27}$ :

Não se faz desenvolvimento sem seres humanos saudáveis. Parece óbvio, mas se o "rascunho zero" (draft zero) do documento oficial das Nações Unidas para a Conferência sobre Desenvolvimento Sustentável $($ Rio +20$)$ não traz qualquer referência à saúde humana, o óbvio precisa ser dito e enfatizado, para garantir espaço no mundo real. Por isso, a Fiocruz elaborou cinco parágrafos que ressaltam a relevância dos determinantes sociais e ambientais da saúde para o desenvolvimento sustentável e encaminhou ao Ministério da Saúde, que por sua vez levou ao Ministério das Relações Exteriores para ser remetido à ONU, na expectativa de que a questão conste na próxima versão do documento oficial ${ }^{28}$.

Esse documento, intitulado O futuro que queremos, serviu como orientador ao processo de elaboração da Agenda do Desenvolvimento Sustentável $2030^{29}$ e definição dos 17 Objetivos do Desenvolvimento Sustentável (ODS).

Nessa nova agenda, nota-se uma maior conexão entre os pilares econômicos, sociais e ambientais. Embora o tema da saúde se apresente de forma expressa no Objetivo $3^{\circ}$ (Garantir vidas saudáveis e bem-estar para todos em todas as idades), verifica-se sua transversalidade em praticamente todos os demais, como no Objetivo $2^{\circ}$ (Acabar com a fome, alcançar a segurança alimentar e melhorar a nutrição e promover a agricultura sustentável); no Objetivo $10^{\circ}$ (Reduzir a desigualdade dentro e entre países; e no Objetivo $13^{\circ}$ (Adotar medidas urgentes para combater as mudanças climática e seus impactos); entre outros.

As audaciosas metas previstas para o ODS $3^{\circ}$ - como "acabar com as epidemias de AIDS, tuberculose, malária e de doenças tropicais negligenciadas"; "reduzir à metade o número de mortes e lesões causadas por acidentes de tráfego" etc. - não dão conta da amplitude e ambição desse Objetivo, que só será possível a partir da intersetorialidade e conexão com os demais ODS.

\footnotetext{
27 “Graças ao esforço da Fiocruz, do Ministério da Saúde, da Organização Pan-Americana da Saúde, da diplomacia brasileira e de parceiros como o Centro Brasileiro de Estudos de Saúde (Cebes) e a Associação Brasileira de Saúde Coletiva (Abrasco), o tema saúde e população ganhou oito parágrafos - do 138 ao 146." Rio+20: sustentabilidade e saúde indissociáveis. Portal Fiocruz. Disponível em: <http://www.fiocruz. br/omsambiental/cgi/cgilua.exe/sys/start.htm?infoid=377\&sid=13>. Acesso em: 31 jan. 2017.

${ }^{28}$ BUSS, Paulo Marchiori. Só há desenvolvimento sustentável com uma população saudável. 2013. Disponível em: <http://www.sauderio20.fiocruz.br/index.php/entrevistas/70-so-ha-desenvolvimentosustentavel-com-uma-populacao-saudavel>. Acesso em: 15 out. 2013.

${ }^{29}$ UNITED NATIONS. A/70/L1. Transforming our world: the 2030 Agenda for Sustainable Development. Disponivel em: <http://www.un.org/ga/search/view_doc.asp?symbol=A/RES/70/1>. Acesso em: 31 jan. 2017.
} 
Na tentativa de lidar com esses desafios e num panorama em que há a dificuldade de reconhecer compromissos factíveis e responsabilidades compartilháveis, os Estados promovem a ampliação das agendas das organizações internacionais e reforçam a necessidade de se ampliar o diálogo e a coordenação de ações entre os países e outros atores.

\section{Atores}

No que diz respeito aos atores que participam da construção do Direito Sanitário presentes no âmbito internacional, podemos classificá-los em: atores tradicionais, como Estados e organizações internacionais, próprias da saúde ou não, e novos atores.

$\mathrm{Na}$ concepção normativa de Estado, o princípio da soberania traduz-se em duas regras na arena internacional: a igualdade formal dos Estados e a não intervenção ${ }^{30}$. Entretanto, as assimetrias entre os Estados são evidentes em múltiplas esferas - políticas, econômicas e sociais -, que acabam por repercutir em seus perfis e características; podendo ser classificados como superpower, emergentes, status quo, ou maioria silenciosa.

Os Estados se organizam em grupos de interesses regionais, políticos e econômicos. As alianças constituídas, contudo, podem acirrar algumas tensões pré-existentes entre Norte versus Sul, superpotências versus resto do mundo, Ocidente versus países islâmicos, membros do Conselho de Segurança da ONU versus demais membros das Nações Unidas.

Ante tal complexidade, e já bastante analisada pelas teorias das relações internacionais, não há de se estranhar a (in)coerência dos Estados em sua atuação no cenário internacional: interesses nacionais versus altruístas, a (ausência de) transparência e a dificuldade de transformar suas propostas em ações.

Nos últimos anos, os temas de saúde têm ficado mais presentes nas discussões em ambientes diversos das tradicionais agências especializadas de saúde, como a OMS e a Organização Pan-Americana da Saúde (OPAS) ${ }^{31}$.

Como consequência, uma ampla gama de organizações intergovernamentais interfere na elaboração de normas internacionais que impactam a saúde. Os acordos da OMC, por exemplo, têm impactos diretos e indiretos sobre a saúde:

Os Estados adotaram uma série de normas de exceção ao princípio da cláusula da nação mais favorecida, devendo destacar-se o Acordo sobre a Aplicação de Medidas Sanitárias e Fitossanitárias, pelo qual se define a regra de que "nenhum Membro deve ser impedido de adotar ou aplicar medidas necessárias à proteção

\footnotetext{
${ }^{30}$ VELASCO E CRUZ, S. Globalização, Democracia e Ordem Internacional. Campinas: Editora Unicamp, 2004.

${ }^{31}$ ALLEYNE, George A. O. A saúde pública internacional e global: governança e questões éticas. 2007. Disponível em: <http://files.bvs.br/upload/S/1555-8746/2007/vn4/a43-63-1.pdf>. Acesso em: 13 set. 2013.
} 
da vida ou da saúde humana, animal ou vegetal, desde que tais medidas não sejam aplicadas de modo a constituir discriminação arbitrária ou injustificável entre Membros em situações em que prevaleçam as mesmas condições, ou uma restrição velada ao comércio internacional ${ }^{32}$.

Verifica-se, também, um número crescente de organizações internacionais e regionais paralelas ao sistema das Nações Unidas. Tais organizações, com mandato dos países-membros, têm atuado na construção de normas relacionadas à saúde. Na região das Américas, por exemplo, se verifica um grande número de organismos que abordam a temática da saúde, tais como a Comunidade Andina das Nações (CAN), a Comunidade do Caribe (Caricom), o Sistema de Integração Centro-americano (Sica), o Mercado Comum do Sul (Mercosul), a Aliança Bolivariana para os Povos de Nossa América (Alba) e a Unasul ${ }^{33}$.

Incluem-se, ainda, os arranjos políticos e econômicos e os blocos de integração regionais, que direta ou indiretamente atuam na questão da saúde, tais como a União Africana (UA), a União Europeia (UE), a Organização dos Estados Americanos (OEA), a Caricom, a Liga Árabe, a Associação das Nações do Sudeste Asiático (Ansa) e a Associação Sul-Asiática para a Cooperação Regional (Saarc), a Comunidade dos Países de Língua Portuguesa (CPLP), os Brics, a Aliança do Pacífico, entre outros.

Pergunta-se, entretanto, qual o interesse dos Estados: fortalecer uma coordenação coerente ou adaptá-la de acordo com seus interesses e zonas de influência?

Também tem havido uma proliferação do que se convenciona chamar de "novos atores" na saúde internacional, atores da sociedade civil e do setor privado ${ }^{34}$. Estes incluem uma variedade de organizações não governamentais (ONGs), fundações e organizações sem fins lucrativos.

As ONGs são entidades constituídas segundo o direito interno de cada Estado e não têm personalidade jurídica de Direito Internacional, mas possuem autoridade científica ou prestígio internacional graças à eficiência de sua atuação

\footnotetext{
${ }^{32}$ SOARES, S. F. S. O direito internacional sanitário e seus temas: apresentação de sua incômoda vizinhança. Revista de Direito Sanitário, São Paulo, v. 1, n. 1, nov. 2000. Disponível em: <http://www.revistas.usp.br/ rdisan/article/view/13076>. http://dx.doi.org/10.11606/issn.2316-9044.v1i1p49-88.

33“"La dimensión social, y em particular los temas de salud, han adquirido mayor relevância; se han ampliado las iniciativas de intregración y/o cooperación em el área de la salud em las Américas. Estas iniciativas responden a los compromissos que han assumido los gobiernos de la Región em diversos encuentros y foros internacionales tales como las Cumbres de Presidentes y de Ministros de Salud de los organismos subregionales, como por ejemplo, Comunidad Andina de Naciones (CAN), el Mercado Común del Sur (MERCOSUR), el Sistema de Integración Centroamericana (SICA), la Comunidad del Caribe (CARICOM), la Alianza Bolivariana para los Pueblos de Nuestra América (ALBA), y mas recentemente, la Unión de Naciones Sudamericanas (UNASUR)". BOLIS, M.; CAMPOS, R. F. América latina: espacios de avance em torno al derecho a la salud. In: DELDUQUE, Maria Célia et al. (Orgs.). El derecho desde la calle: introducción critica al derecho a la salud. Brasília: Fundação Universidade de Brasília, CEAD, 2012. p. 97-106.

${ }^{34}$ ALLEYNE, George A. O. op. cit.
} 
aos meios financeiros de grande envergadura de que gozam. Em grande parte, são financiadas por poderosos grupos privados empresariais, representando fortes interesses econômicos privados. Também pela força de convencimento de que desfrutam junto à opinião pública internacional, ganham extraordinária relevância nos assuntos da saúde pública internacional ${ }^{35}$.

\begin{abstract}
A saúde global é uma arena única de governança que integra cientistas, profissionais médicos, filantropos, governantes, instituições internacionais com história de atuação em comunidades locais e celebridades que se autodefinem como porta-vozes. A governança global em saúde envolve uma mescla de vários Estados, atores não estatais públicos e privados e, dessa forma, se desenvolve para além do papel institucional da OMS e dos ministérios de saúde dos Estados-Membros ${ }^{36}$. (Tradução livre)
\end{abstract}

Questionam-se com veemência as formas como atuam as grandes incorporações empresariais, tais como indústrias farmacêuticas e produtoras de tabaco e alimentos, que por sua influência no PIB dos países constroem um forte lobby junto aos governos para que adotem ou não normas internacionais ou legislações internas que lhes favoreceriam ou prejudicariam.

Também revela-se profundamente inquietante que algumas fundações privadas internacionais concedam investimento para pesquisas cientificas e ações de cooperação que gerenciam e propagam a favor dos interesses de seus parceiros e financiadores.

A diversidade de atores internacionais envolvidos ativamente na área da saúde, combinada com críticas generalizadas das Nações Unidas e suas agências especializadas, levou alguns comentaristas a sugerir a redução do papel das organizações intergovernamentais na governança da saúde global ${ }^{37}$. Alguns têm enfatizado de forma preocupante uma "transferência de poder" dos Estados e organizações intergovernamentais para os atores do setor privado.

\title{
IV. Processos políticos de negociação de normas internacionais relacionadas à saúde
}

Nesse sentido, os processos políticos de negociação de normas internacionais relacionadas à saúde sofrem influências das mais variadas esferas. Os foros internacionais

\footnotetext{
${ }^{35}$ HARRINGTON, J; STUTTAFORD, M. Global health and human rights: legal and philosophical perspectives. Routledge, 2012.

36“"Global health is a unique arena of governance that integrates scientists, medical practitioners, philanthropists, governments, international institutions with grandmothers in local communities and self-styled celebrity advocates. Global health governance involves an amalgamation of various state, non-state, private and public actors and as such has developed beyond the institutional role of the WHO and the state-based ministries of health". HARMAN, S. Global health governance (Global Institutions). Routledge, 2011. p. 2.

${ }^{37}$ HARRINGTON, J; STUTTAFORD, M. op. cit.
} 
funcionam como espaços de atuação da diplomacia da saúde global que tratam dos processos de negociação que configuram e gerenciam o ambiente da política global para a saúde ${ }^{38}$.

Embora a OMS é a autoridade que direciona os assuntos relativos à saúde dentro do Sistema das Nações Unidas, outras questões de saúde que geram preocupações para a política externa e a segurança humana podem ser destaque na Assembleia Geral da $\mathrm{ONU}^{39}$, onde os Estados-Membros podem renegociar e aprovar maiores compromissos, almejando um impacto mais amplo. Entretanto, em apenas duas oportunidades temas propriamente de saúde tiveram destaque nessa reunião: quando foi discutida a luta contra o HIV/Aids, em $2006^{40}$, e as DCNT, em $2010^{41}$.

Em que pesem as normas de direito internacional sanitário, próprias da OMS - como a Convenção-Quadro para o Controle do Tabaco e o Regulamento Sanitário Internacional -, não é verdade que todo desenvolvimento de normas de saúde do sistema das Nações Unidas seja de sua exclusividade. Muitos outros membros do sistema da ONU estão envolvidos nessa tarefa. "As instituições responsáveis pelo desenvolvimento e aplicação de regulamentos jurídicos na área da saúde são numerosos e diversos" ${ }^{\text {"22 }}$ (tradução livre).

Muitas questões de saúde também são abordadas pelo Programa das Nações Unidas para HIV/AIDS (Unaids), pelo Fundo das Nações Unidas para a População (Unfpa) e pelo Fundo das Nações Unidas para a Infância (Unicef). Além disso, a Organização Internacional do Trabalho (OIT), a OMC, a Agência das Nações Unidas de Assistência aos Refugiados Palestinos (Unrwa), a Organização das Nações Unidas para Agricultura e Alimentação (FAO), a Agência Internacional de Energia Atômica (Aiea), o Programa das Nações Unidas para o Meio Ambiente (Pnuma), o Escritório das Nações Unidas para Drogas e Crime (Unodc) e o Banco Mundial, entre outros, desempenham um papel ativo na construção de normas relacionadas à saúde.

A Tabela 1 apresenta alguns exemplos de normas de direito internacional relacionadas à saúde que foram formuladas por organizações internacionais:

\footnotetext{
${ }^{38} \mathrm{KICKBUSCH}$, I; WOLFGANG, H; GAUDENZ, S. Addressing global health governance challenges through a new mechanism: the proposal for a Committee $\mathrm{C}$ of the World Health Assembly. The Journal of Law, Medicine \& Ethics, p. 550-563, 2010. Disponível em: <http://graduateinstitute.ch/files/live/sites/iheid/files/sites/ globalhealth/shared/1894/Committee\%20C\%202010.pdf>.

${ }^{39}$ Reconhecendo o papel intrínseco da saúde para a realização dos objetivos internacionais, a Assembleia Geral adotou de forma unânime a Resolução sobre a Saúde Global e Política Externa. UNITED NATIONS. A/RES/65/95. Resolution adopted by the General Resolution adopted by the General Assembly. Disponível em: <http://www. who.int/mental_health/policy/resolution_global_health_and_foreign_policy.pdf >. Acesso em: 31 jan. 2017.

${ }^{40}$ NACIONES UNIDAS. A/RES/60/262. Declaración política sobre el VIH/SIDA. Disponível em: <http://www. un.org/en/ga/search/view_doc.asp?symbol=A/RES/60/262\&referer=http://www.un.org/depts/dhl/ resguide/r60_resolutions_table_eng.htm\&Lang=S>. Acesso em: 31 jan. 2017.

${ }^{41}$ NACIONES UNIDAS. A/Res/65/238. Alcance, modalidades, formato y organización de la Reunión de Alto Nivel de la Asamblea General sobre la Prevención y el Control de las Enfermedades no Transmisibles. Disponível em <http://www.un.org/en/ga/search/view_doc.asp?symbol=A/RES/65/238\&referer=http:// www.un.org/depts/dhl/resguide/r65_resolutions_table_eng.htm\&Lang=S>. Acesso em: 31 jan. 2017.

42" The institutions responsible for the development and application of legal regulations in the field of health are both numerous and diverse". (BÉLANGER, M. General aspects of global health law. In: health law: na introduction. Cottenham: Cambridge Scientific Publishers, 2011. p. 22.)
} 
Tabela 1. Normas internacionais relacionadas à saúde.

\begin{tabular}{|c|c|c|}
\hline Tipos normativos & $\begin{array}{l}\text { Organização } \\
\text { internacional }\end{array}$ & Temas de saúde relacionados \\
\hline $\begin{array}{l}\text { Legislação de comércio } \\
\text { internacional (Trips, Trips Plus etc.) }\end{array}$ & OMC & Comércio de produtos farmacêuticos. \\
\hline $\begin{array}{l}\text { Direito Internacional dos direitos } \\
\text { humanos (DUDH, DUBDH etc.) }\end{array}$ & ONU, Unesco & $\begin{array}{l}\text { Proteção dos direitos humanos dos } \\
\text { indivíduos. }\end{array}$ \\
\hline $\begin{array}{l}\text { Legislação ambiental internacional } \\
\text { (Declarações Estocolmo } 72 \text {, } \\
\text { Eco } 92 \text {, Kyoto, Rio+20 etc.) }\end{array}$ & ONU, Pnuma & $\begin{array}{c}\text { Problemas ambientais com impacto sobre os } \\
\text { problemas de saúde. }\end{array}$ \\
\hline $\begin{array}{l}\text { Legislação internacional do } \\
\text { trabalho (Convenções } 155 \text { e 187) }\end{array}$ & OIT & Segurança e saúde dos trabalhadores. \\
\hline $\begin{array}{l}\text { Regulação internacional } \\
\text { de comércio de alimentos } \\
\text { (Codex Alimentarius) }\end{array}$ & FAO & $\begin{array}{c}\text { Standards para o comércio internacional } \\
\text { de alimentos, normas quanto ao uso } \\
\text { de agrotóxicos, aditivos alimentares, } \\
\text { pesticidas, resíduos de medicamentos } \\
\text { veterinários, substâncias contaminantes, } \\
\text { rotulagem etc. }\end{array}$ \\
\hline $\begin{array}{l}\text { Direito Internacional humanitário } \\
\text { (Convenções de Genebra de } \\
\text { 1949, protocolos adicionais } \\
\text { de } 1977 \text { etc.) }\end{array}$ & CICV & $\begin{array}{l}\text { Proteção da saúde dos combatentes e não } \\
\text { combatentes em tempos de conflito armado. }\end{array}$ \\
\hline
\end{tabular}

Fontes: WTO, ILO, UNEP, UNESCO, FAO, CICV, UN (adaptado pela autora).

Recuperam-se, ainda, os diversos tratados e Resoluções provenientes de outros organismos internacionais regionais, já comentados anteriormente, que podem, por vezes, duplicar os compromissos assumidos pelos governos da região em outros fóruns internacionais de maior alcance. A princípio, a convergência dos temas pode favorecer a otimização das ações, mas pode também culminar em dificuldades.

Os processos de integração regional, normalmente referidos como a formação de blocos econômicos, interferem na produção normativa e no contencioso relativo à saúde $\mathrm{e}^{43}$.

As questões de saúde e do Direito internacional estão intimamente relacionadas. Incluindo as variáveis já destacadas - como os múltiplos interesses dos Estados em sua atuação interna e internacional, além das influências de atores privados na construção das normas de saúde -, verifica-se o panorama do Direito Sanitário Global.

\footnotetext{
${ }^{43}$ VENTURA, D. F. L. Saúde Pública e Integração Regional: tensões entre o direito à saúde e o comércio internacional. In: BOGDANDY, Armin von; PIOVESAN, Flávia; ANTONIAZZI, Mariela Morales (Orgs.). Direitos humanos, democracia e integração jurídica na América do Sul. Rio de Janeiro: Max Planck Institute; Lumen Juris; PUC-SP, 2011. v. 1, p. 449-472.
} 
Direito Sanitário Global é composto por todas as normas legais destinadas a proteger a saúde das pessoas ativamente, interconectando normas elaboradas por organizações internacionais competentes (que correspondem ao direito sanitário internacional) com normas estabelecidas pelos Estados (i.e., direito sanitário nacional $)^{44}$. (Tradução livre)

Dessa forma, o Direito Sanitário Global fornece uma base legal para os compromissos internacionais de saúde e poderia incluir arquiteturas institucionais e processuais para incentivar o seu cumprimento, como mecanismos que possibilitem a assistência financeira e técnica, a troca de informações, experiências, pesquisas científicas e de vigilância, bem como a fiscalização e a resolução de conflitos.

É de suma importância que se aprimore a capacidade dos Estados na negociação e implementação das agendas internacionais de saúde. Uma maior participação da sociedade civil nas discussões de interesse à saúde poderia contribuir para uma ação mais coerente dos Estados, fortalecendo-os frente aos lobbies e interesses emanados por outros atores adversos.

\section{Considerações finais}

A evolução da consciência global sobre o direito humano à saúde coincide com a percepção sobre suas interfaces na esfera política, econômica, de segurança etc. Desse modo, verificam-se variados atores e interesses; temas relacionados à saúde, exemplificados através de algumas normas internacionais com interface na saúde; e o processo político de negociação de normas de interesse à saúde.

Questiona-se a legitimidade e os interesses de alguns atores em seu envolvimento com o tema da saúde, bem como a multiplicação de normativas que produzem efeitos relacionados à saúde dos povos.

O grande desafio no Direito Sanitário Global é a harmonização de temas e a coordenação dos interesses dos atores nos processos políticos de negociação de normas internacionais de interesse à saúde. No cenário impulsionado pela globalização, os Estados e o setor da saúde precisam recuperar seu objetivo final: a proteção da saúde.

No cenário difuso atual, reitera-se a defesa do fortalecimento do papel dos Estados como os principais atores internacionais, de forma responsável e como garantidores legítimos do direito à saúde.

\footnotetext{
44"Global Health Law is made up of all the legal regulations designed to protect people's Health actively, interconnecting regulations drawn up by competent international organisations (wich correspond to international Health law) with regulations established by States (i.e. national health law)". (BÉLANGER, M. op. cit. p. 5.)
} 


\section{Referências}

ALLEYNE, George A. O. A saúde pública internacional e global: governança e questões éticas. 2007. Disponível em: <http://files.bvs.br/upload/S/1555-8746/2007/vn4/a43-63-1. pdf $>$. Acesso em: 13 set. 2013.

ALMEIDA, Celia. A experiência da Fiocruz na formação de profissionais em saúde global e diplomacia da saúde: base conceitual, estrutura curricular e primeiros resultados. Reciis, Rio de Janeiro, v. 4, n. 1, p. 148-164, mar. 2010. Fundação Oswaldo Cruz. Disponível em: <http://www.reciis.icict.fiocruz.br/ index.php/reciis/article/view/721/1366>. Acesso em: 10 set. 2013. 10.3395/reciis.v4i1.355pt.

ATLAS, Ronald M. The threat of bioterrorism returns the fear of smallpox. Current Opinion in Microbiology, v. 1, 1998.

BÉLANGER, M. Introduction à un droit mondial de la santé. Paris: Archives Contemporaines, 2009.

BERMURDEZ, J. A. Z; OLIVEIRA, M. A; CHAVES, G. C. O Acordo TRIPS da OMC e os desafios para a saúde pública. In: BERMUDEZ, Jaz; OLIVEIRA, M; ESHER, A. (Orgs.). Acceso a medicamentos: derecho fundamental, papel del Estado. Rio de Janeiro: Escola Nacional de Saúde Pública, Fundação Oswaldo Cruz, 2004. p. 69-89.

BOLIS, M.; CAMPOS, R. F. América latina: espacios de avance em torno al derecho a la salud. In: DELDUQUE, Maria Célia et al. (Orgs.). El derecho desde la calle: introducción critica al derecho a la salud. Brasília: Fundação Universidade de Brasília, CEAD, 2012. p. 97-106.

BUSS, Paulo Marchiori. Só há desenvolvimento sustentável com uma população saudável. 2013. Disponível em: <http://www.sauderio20.fiocruz.br/index.php/entrevistas/70-so-hadesenvolvimento-sustentavel-com-uma-populacao-saudavel $>$. Acesso em: 15 out. 2013.

et al. Governança em saúde e ambiente para o desenvolvimento sustentável. Ciênc. saúde coletiva, v. 17, n. 6, p. 1479-1491, 2012. Disponível em: <http://www.scielosp.org/pdf/csc/v17n6/ v17n6a12.pdf>. Acesso em: 15 out. 2013. http://dx.doi.org/10.1590/S1413-81232012000600012.

CASTRO, L. P. G; FERREIRA, F. P. O direito à saúde e a globalização. Revista Anhanguera, v. 11, n. 1, p. 61-87, dez. 2010.

FERNANDEZ, L. A. L. A crise econômica Europeia e as repercussões nos sistemas de saúde. São Paulo, Conferência, 21, nov. 2012. Conferência realizada na FSP/USP.

FILDER, D. P. Trade, foreign policy, diplomacy and health: International Law. [homepage na internet]. [Disponível em: < http://www.who.int/trade/distance_learning/gpgh/gpgh7/en/ index1.html >. Acesso em: 16 fev. 2017.

GOSTIN, L.O; TAYLOR, A. L. Global health law: a definition and grand challenges. Public Health Ethics, v. 1, n. 1, p. 53-63, 2008. Disponível em: <https://academic.oup.com/phe/ article-lookup/doi/10.1093/phe/phn005>. https://doi.org/10.1093/phe/phn005.

HARMAN, S. Global health governance (Global Institutions). Routledge, 2011. 
HARRINGTON, J; STUTTAFORD, M. Global health and human rights: legal and philosophical perspectives. Routledge, 2012.

IAEA. INTERNATIONAL ATOMIC ENERGY AGENCY. Update on Seawater Radioactivity Concentrations at TEPCO’s Fukushima Daiichi Nuclear Power Station. 2013. Disponível em: <https:// www.iaea.org/newscenter/news/2013/seamonitoring151013.pdf>. Acesso em: 16 out. 2013.

KICKBUSCH, I. Action on global health: addressing global health governance challenges. Public Health, v. 19, n. 119, p. 969-973, 2005 http://dx.doi.org/10.1016/j.puhe.2005.08.008.

Global health diplomacy: training across disciplines. In: NOVOTNY, Thomas E. et al. Bulletin of the World Health Organization, n. 85, p. 971-973, 2007.

; WOLFGANG, H; GAUDENZ, S. Addressing global health governance challenges through a new mechanism: the proposal for a Committee $\mathrm{C}$ of the World Health Assembly. The Journal of Law, Medicine \& Ethics, p. 550-563, 2010. Disponível em: $<$ http://graduateinstitute. ch/files/live/sites/iheid/files/sites/globalhealth/shared/1894/Committee\%20C\%202010.pdf>.

MERCADO COMUM DO CONE SUL. Laudos: protocolo de olivos para a solução de controvérsias no Mercosul: tribunal permanente de revisão. Montevideo, Mercosur. Disponível em: <http://www.mercosur.int/innovaportal/v/440/2/innova.front/laudos $>$. Acesso em 18 fev. 2017.

MOROSINI, Fabio C. The MERCOSUR and WTO Retreaded Tires Dispute: Rehabilitating Regulatory Competition in International Trade and Environmental Regulation. In: INAUGURAL CONFERENCE, 2008, Switzerland. Geneva: Society of International Economic Law (SIEL). Disponível em: <https://papers.ssrn.com/sol3/papers2.cfm?abstract_ id=1154710\#\#>. Acesso em: 18 fev. 2017. http://dx.doi.org/10.2139/ssrn.1154710.

RODRIGUES, W. C. V;; SOLER, O. Licença compulsória do efavirenz no Brasil em 2007: contextualização. Revista Panamericana de Salud Publica, v. 26, n. 6, p. 553-559, 2009.

RUGGIE, J. At home abroad, abroad at home: international liberalization and domestic stability in thenew worldeconomy. Millennium: journal of international studies, v.24,n.3,p.507-526, 1994. Disponível em: <http://journals.sagepub.com/doi/pdf/10.1177/03058298950240031301>.

SACARDO, D. P.; FORTES, P. A. C.; TANAKA, O. Y. Novas perspectivas na gestão do sistema de saúde da Espanha. Revista Saúde Sociedade, São Paulo, v. 19, n. 1, p. 170-179, 2010.

SOARES, S. F. S. O direito internacional sanitário e seus temas: apresentação de sua incômoda vizinhança. Revista de Direito Sanitário, São Paulo, v. 1, n. 1, nov. 2000. Disponível em: <http://www.revistas.usp.br/rdisan/article/view/13076>. http://dx.doi.org/10.11606/ issn.2316-9044.v1ilp49-88.

STEPHEN, C.; DAIBES, I. Defining features of the practice of global health research. Global Health Action, n. 3, 2010. Disponível em: <http://www.globalhealthaction.net/index.php/ gha/article/view/5188/5772>. Acesso em: 10 out. 2013. 
TAYLOR, A. L. Global governance, international health law and WHO: looking towards the future. Bull World Health Organ, v. 80, n. 12, p. 1-5, Jan. 2012. Disponível em: <http://www. scielosp.org/scielo.php?script=sci_arttext\&pid=S0042-96862002001200013\&lng=en\&nrm= iso >. Acesso em: 30 ago. 2013. http://dx.doi.org/10.1590/S0042-96862002001200013.

TOBIN, J. The right to health in international law. OUP Oxford, 2012.

TUCKER, Jonathan B. Breaking the deadlock over destruction of the smallpox virus stocks. Biosecurity and Bioterrorism: biodefense strategy, practice and science, v. 9, n. 1, 2011.

VELASCO E CRUZ, S. Globalização, Democracia e Ordem Internacional. Campinas: Editora Unicamp, 2004.

VENTURA, D. F. L. Saúde Pública e Integração Regional: tensões entre o direito à saúde e o comércio internacional. In: BOGDANDY, Armin von; PIOVESAN, Flávia; ANTONIAZZI, Mariela Morales (Orgs.). Direitos humanos, democracia e integração jurídica na América do Sul. Rio de Janeiro: Max Planck Institute; Lumen Juris; PUC-SP, 2011. v. 1, p. 449-472.

WORLD HEALTH ORGANIZATION (WHO). Emergencies preparedness, response: 2013 [homepage da internet]. Disponível em: <http://www.who.int/csr/don/archive/year/2013/ en/index.html >. Acesso em: 30 ago. 2013.

WORLD TRADE ORGANIZATION. Brazil: Measures affecting imports of retreaded tyres [internet]. Geneva, Switzerland: WTO. Disponível em: <https://www.wto.org/english/ tratop_e/dispu_e/cases_e/ds332_e.htm>. Acesso em 18 fev. 2017.

YACH, D; BETTCHER, D. A globalização da saúde pública 1: ameaças e oportunidades. Jornal Americano de Saúde Pública, p. 735-738. 1998.

\section{Agradecimentos}

A autora agradece a Cecília de A. Lopes, Larissa F. A. Cedro e Manoel de A. Amorim pela colaboração na revisão do artigo e ao apoio da Coordenação de Aperfeiçoamento de Pessoal de Nível Superior (Capes).

Roberta de Freitas - Doutoranda em Saúde Global e Sustentabilidade pela Faculdade de Saúde Pública da Universidade de São Paulo; mestre em Direitos Humanos e Relações Internacionais pela Universidad de Sevilla. Assessora de Relações Internacionais em Saúde da Fiocruz e vice-coordenadora do Núcleo de Estudos sobre Bioética e Diplomacia em Saúde (Nethis/Fiocruz). Advogada. Brasília/DF, Brasil. E-mail: roberta.freitas@fiocruz.br. 